\title{
CYTOMORPHOMETRIC ANALYSIS OF BUCCAL CELLS IN BUILDING WORKERS EXPOSED TO POLYCYCLIC AROMATIC HYDROCARBON IN AND AROUND COIMBATORE DISTRICT
}

\author{
SARANYA RAMALINGAM SINGARAVELU, SUSHMITHA SRINIVASAN, DEEPAK DINESH
}

PG and Research Department of Biotechnology, Hindusthan College of Arts and Science Nava India, Coimbatore, Tamilnadu, India

Email: rssaranya.ya@gmail.com

Received: 27 Dec 2016, Revised and Accepted: 12 Apr 2017

\section{ABSTRACT}

Objective: Building workers are exposed to a mixture of chemicals and polycyclic aromatic hydrocarbons at the time exposure by inhalation which is suspected to cause genetic damage. The aim of the study was to assess the level of genetic damage in south Indian building workers are exposed to PAHs.

Methods: 30 Building workers and standardized control groups are examined for frequencies of micronuclei in buccal epithelial cells.

Results: The genetic damage observed in the buccal cells of building workers was significantly higher than in controls. Chewing also related to genetic damage since the observed in PAHs exposed groups with chewers was significantly higher than non-chewing workers.

Conclusion: Occupational exposure of PAHs from building workplaces has been associated with increased genetic damage and chewers represent an additional risk factor. Exposure to PAHs may be related to increased risk of cancer in building workers.

Keywords: Occupational exposure, Building workplace, Micronucleus test

(C) 2017 The Authors. Published by Innovare Academic Sciences Pvt Ltd. This is an open access article under the CC BY license (http://creativecommons.org/licenses/by/4.0/) DOI: http://dx.doi.org/10.22159/ijcpr.2017v9i3.19600

\section{INTRODUCTION}

Polycyclic aromatic hydrocarbons are an organic compound that are colourless, white or pale yellow solids. It composed of two or more aromatic benzene rings. They have toxic effects of the organism through various routes and usually found as a mixture containing two or more of compounds. Then some of the polycyclic aromatic hydrocarbons are manufactured in the industry. The major source of the polycyclic aromatic hydrocarbons is the incomplete combustion of organic material such as coal, oil, and wood [1].

The polycyclic aromatic hydrocarbons may be contained in asphalt used for the construction of roads, roofing tar. There are the three sources of polycyclic aromatic hydrocarbon they are pyrogenic, petrogenic, and biological are the major sources. Hydrocarbon is exposed to the innate toxicity and affect health impact. Occupational exposures to a high level of pollutants mixture containing the polycyclic aromatic hydrocarbon have resulted in symptoms such as vomiting, nausea, diarrhea. If the long-term exposures means it leads to cause some affects they are decreased immune function, cataract, kidney and liver damage, mutations and developmental malformations [2]. The EPA has classified into several types they are benzo perylene, dibenzo pyrene, naphthalene, perylene. Building workers are exposed to the various occupational environment. They are present in the form of gases, fumes, vapours and by inhalation. The workers are exposed to polycyclic aromatic hydrocarbons in the asphalt preparation. The low amount of polycyclic aromatic hydrocarbons are present in asphalt fumes. The workers are exposed to less amount of polycyclic aromatic hydrocarbons but they have affected means it causes long term effects [1].

The aim of the study is to analyze the genotoxicity from the building workers who are exposed to polycyclic aromatic hydrocarbons. To check whether the workers are affected by exposure of polycyclic aromatic hydrocarbons and also the habitant and non-habitant of tobacco chewers, smoking and alcoholic consumption and also to determine the nuclear damages of the workers.

\section{MATERIALS AND METHODS}

The present study was conducted in rural areas of Tamil Nadu state, South India in accordance with Helsinki declaration. The written consent from the subjects involved in the study was obtained. The study population included 60 subjects, comprising of 30 users and 30 nonusers aged between 25-45 y. Both control and experimental subjects were from same socio-economic status and were involved in the same type of occupation. Individuals were clinically healthy and had not been exposed to known genotoxic agents and were matched by age and sex. Exclusion criteria for the subjects included the presence of any self-reported acute illness, chronic diseases, heart failure, malignant, liver or kidney failure, diabetes mellitus, history of alcohol or drug use and smoking habit for at least last three years [3].

Users and controls were subdivided into 3 groups; Group I-smoking individuals between 25-45 y of age, Group II-smoking with chewing habits between 25-45 y of age and Group III-chewers between 25-45 y of age. Before sampling, each subjects rinsed their mouth thoroughly with tap water. Genotoxicity testing for evaluation of cells is convenient that each participant had a mouthwash with water before sample collection in order to remove any food or artifacts that may interfere with analysis. The sample will be collected with a gentle swab of the toothpick of the right and left cheeks and the samples are immersed in the saline or phosphate and smeared onto a clear glass slide and immediately fixed with $95 \%$ ethanol for a minimum of $15 \mathrm{~min}$ [3].

A minimum of two smears was taken from each subject to give 100 cells per subject (50 cells per smears). Collected smears were immediately fixed using 3:1 methanol: acetic acid for $15 \mathrm{~min}$. The cells were stained using the Feulgen plus fast-green method, following the procedure of Moraes et al. [2005], with a minor modification: fastgreen $0.5 \%$ solution in ethyl alcohol was used for $30 \mathrm{sec}$.

Two hundred cells per subject that were unfolded with clear outline were selected for the study. Only smears with unclamped, monolayered and consistent squamous cells were used for analysis. Cells were analyzed for cellular diameter (CD), nuclear diameter (ND), and nucleo cellular (N/C) ratio using a microscope equipped with a $100 \mathrm{X}$ objective (Olympus 20i, Japan) and a $2.25 \mathrm{X}$ video projection lens (Nikon CCTV/Microscope Adapter, Yokohama, Japan). The received images were transmitted to a video camera for display on a video monitor (Sony, Tokyo, Japan). A screenshot of each slide was captured, saved, and transferred to the computer for image analysis. Analysis was done using Magnus Pro Software. The 
statistical significance was determined by student's t-test. P value less than 0.05 was accepted as statistically significant. The relationship between ages with duration of chewers use was evaluated via Pearson correlation test [3].

Table 1: Characteristics of the study population

\begin{tabular}{lll}
\hline Characteristics & Exposed groups & Control groups \\
\hline Number & 30 & 30 \\
Age & $25-45$ & $25-45$ \\
Smoking (group I) & 10 & 10 \\
Smoking with chewers (group II) & 10 & 10 \\
Chewers (group III) & 10 & 10 \\
\hline
\end{tabular}

\section{RESULTS}

Table 1 presents the general characteristic of the study population. Table 2 represents the results of cytomorphometric analysis. The buccal mucosa of healthy volunteers with smoking habit alone smoking with chewing habit and chewing alone showed a significant variation in the size of mean ND and CD when compared with the respective controls. The results showed that mean ND in buccal mucosa was noticeably elevated $(\mathrm{p}<0.05)$ in users group $(0.45 \pm 0.23$, $0.53 \pm 0.24,0.48 \pm 0.25 \mu \mathrm{m})$ than in the control group $(0.7 \pm 2.0$, $8.04 \pm 0.7,8.3 \pm 1.2 \mu \mathrm{m})$, and mean CD in buccal mucosa was markedly lower $(\mathrm{p}<0.05)$ in user group $(61.0 \pm 0.7,60.8 \pm 0.5,60.9 \pm 0.4 \mu \mathrm{m})$ than in the control group $(61.2 \pm 0.8,60.7 \pm 0.6,61.0 \pm 0.9 \mu \mathrm{m})$. In addition, mean $\mathrm{N} / \mathrm{C}$ ratio in users group $(0.43 \pm 0.27,0.55 \pm 0.27,0.65 \pm 0.19)$ was apparently higher than in the control group $(0.43 \pm 0.27$, $0.55 \pm 0.27,0.48 \pm 0.25)(\mathrm{p}<0.05)$.

Table 2: Characteristics of exposed controls and groups comparison of mean values of cellular diameter, nuclear diameter, and nuclearcytoplasmic ratio in buccal epithelial cells of controls and respect to smoking, smoking with chewers and chewers

\begin{tabular}{llll}
\hline Parameters & Group & Group I & Group II \\
\hline Nuclear & Controls & $0.7 \pm 2.0$ & $8.04 \pm 0.7$ \\
Diameter & Users & $0.3 \pm 2.1$ & $7.8 \pm 1.01$ \\
Cytoplasmic & Controls & $61.2 \pm 0.8$ & $60.7 \pm 0.6$ \\
Diameter & Users & $61.0 \pm 0.7$ & $60.8 \pm 0.5$ \\
Nuclear: cytoplasmic & Controls & $0.45 \pm 0.23$ & $0.53 \pm 0.24$ \\
Diameter. & Users & $0.43 \pm 0.27$ & $0.55 \pm 0.27$ \\
\hline
\end{tabular}

$\mathrm{P}<(0.05)$

\section{DISCUSSION}

PAHs have been identified as cancer-inducing chemicals for animals and humans [4]. Also, there is a sufficient evidence that exposures in the occupational settings are carcinogenic to human. High occupational exposure to toxic substances such as PAHs and other petroleum products are the main toxicants to the exposed subject [5]. It is generally accepted that PAHs may cause direct/indirect genotoxic effects, thus genotoxicity biomarkers have a received a considerable interest as tools for detecting human genotoxic exposure and effects. Searching of association between biomarkers will help to select most advantageous biomarkers for further competent monitoring of various human exposure [6].

Buccal cells are the primary barrier for the inhalation and are capable of metabolising proximate carcinogens to reactive products $[7,8]$. Approximately $90 \%$ of human cancers originate from epithelial cells [9]. The oral epithelial cells represent a target site for early genotoxic events induced by carcinogenic agents entering the body via inhalation and ingestion. Exfoliated buccal epithelial cells were used to evaluate the genotoxic effects and are an efficient tool for bio monitoring studies $[10,11]$.

Cigarette smoking is one of the daily life related public health threads that may influence the rate of cytogenetic damage [12]. Since cigarette smoke contains about 50 potent carcinogens, including polyaromatic hydrogen carbons (PAHs) and other organic chemicals, Hence, the increase in cellular and nuclear diameter by cigarette smoking is biologically believable.

In the present study, increased occurrence of abnormal nucleus and cytoplasm ratio was noticed in the exfoliated cells of the chewer's users. The increase in age and extent of chewers use showed a significantly higher frequency of every investigated cytological change. This finding is positively associated with oral carcinogenesis and support earlier investigations that disclose statistically significant decline in mean cytoplasmic area of cells taken from the normal buccal mucosa of tobacco chewers [13-16]. The buccal mucosa collected from 25-45 y of age group chewer's users also showed a significant result when compared to that of controls.

The increase in nuclear size is an indicator of cellular damage in tobacco users. Decreased cellular turnover as a result of prolonged chewers use the following ageing would result in more number of mature cells with large nuclei in the smear [16].

This also accords with our earlier observations, which showed that a reduction in the size of ND and increase in the size of $\mathrm{CD}$ in chewers with a smoking habit and smoking habit alone than those with the habit of using chewers alone [2].

The results observed in the present study were, a clear proportional increase in CD was shown in those aged 25-45, a decrease in ND chewers users and a steady increase in N/C ratio from control individuals to chewers users. In addition to this age-dependent increase in abnormal nucleus and cytoplasm ratio was observed in chewers.

\section{CONCLUSION}

Above study has been concluded that the chewers have the morphological and pathological changes among the chewers. The study report shows that cytomorphological and the genotoxicity has been seen in chewers of college students. We concluded that visual communication students will be affected by morphological and pathological changes it leads causes of cancer. So we concluded that volunteers are affected for an oral health problem. This problem will be overcome by to reduce the tobacco consumption.

\section{ACKNOWLEDGEMENT}

The authors are grateful to the authorities of Hindusthan Institutions, Coimbatore for providing facilities and encouragement. Thanks for the author for supporting and encouragement. The thankful for the volunteers for their cooperation at the time of sample collection. 


\section{CONFLICT OF INTERESTS}

Declared none

\section{REFERENCES}

1. Sudha S, Sree Jaya S, Saranya RS, Varun S. Evalution of DNA damage and oxidative stress in road pavement workers occupationally exposed to polycyclic aromatic hydrocarbons. Int Conference Adv Agric Biol Environ Sci; 2014. p. 15-3.

2. Gemitha G, Sudha S, Saranya RS. Induction of cytomorphological changes in buccal cells of khaini chewing south India population. Asian J Med Clin Sci 2013;2:48-50.

3. Saranya RS, Sudha S. Cytomorphological changes in buccal epithelial cells of khaini chewers in different age groups. Asian J Biomed Pharm 2014;30:43-47.

4. Anyakoraz CA, Ogbeche KA, Palmer P, Coker H, Ukpo G, Ogah C. GC/MS analysis of polynuclear aromatic hydrocarbons in sediment samples from the Niger delta region. Chemosphere 2005;60:990.

5. Norppa H. Cytogenetic biomarkers. In: Buffler P, Rice J, Baan R, Bird M, Boffetta P. editors. Mechanisms of carcinogenesis: contributions of molecular epidemiology; 2004. p. 179-5.

6. Saranya RS, Sudha S. Frequency of micronuclei in exfoliated buccal epithelial cells of sand moulding foundry workers in Tamilnadu, South India. World J Pharm Res 2014:2:355-64.

7. Shabana P, Rawat RS. Assessment of Occupational Hazard in Iron Foundry Workers at Nunihai Industrial Estate, Agra. Asian J Exp Biol Sci 2010:1:197-200.

8. Rosin MP, German J. Evidence for chromosome instability in vivo in Bloom syndrome: increased numbers of micronuclei in exfoliated cells. Hum Gene 1985;71:187-91.

9. Holland N, Bolognesi C, Volders MK, Bonassi S, Zeiger E, Knasmueller S. The micronucleus assay in human buccal cells as a tool for biomonitoring DNA damage: The human project perspective on current status and knowledge gaps. Mutat Res 2008;659:93-108.

10. Zaridze DG, Blettner M, Matiakin EG, Poljakov BP, Stich HF, Rosin MP. The effect of mass use and smoking on the risk of oral leukoplakia. Cancer Detect Prev 1986;9:435-40.

11. Lakhanisky T, Bazzoni D, Jadot P, Joris I, Laurent C, Ottogali M. Cytogenetic monitoring of a village population potentially exposed to a level of environmental pollutant. Mutat Res 1993:319:317-23.

12. Moraes AS, Vidal BC, Guaraldo AMA, Mello MLS. Chromatin supraorganization and extensibility in mouse hepatocytes the following starvation and refeeding. Cytometry 2005;63:94-107.

13. Mustafa G, Hayati MA, Cemal G. The cytomorphological analysis of buccal mucosa cells in smokers. Turk J Med Sci 2011;41:205-10.

14. Acharya S, Tayaar SA, Khwaja T. Cytomorphometric analysis of the keratinocytes obtained from clinically normal buccal mucosa in chronic gutkha chewers. J Cranio Max Dis 2013;2:134-41.

15. Alka HH, Minal SC. Cytomorphometric analysis of buccal mucosa of tobacco chewers. Rom J Morphol Embryol 2010;51:527-32.

16. Goregen M, Akgul HM, Gundogdu C. The cytomorphological analysis of buccal mucosa cells in smokers. Turk J Med Sci 2011;41:205.

17. Prasad H, Ramesh V, Balamurali PD. Morphologic and cytomorphometric analysis of exfoliated buccal mucosal cells in diabetics patients. J Cytol 2010;24:113-7.

\section{How to cite this article}

- Saranya Ramalingam Singaravelu, Sushmitha Srinivasan, Deepak Dinesh. Cytomorphometric analysis of buccal cells in building workers exposed to polycyclic aromatic hydrocarbon in and around coimbatore district. Int J Curr Pharm Res 2017;9(3):95-97. 